CLINICAL STUDY

\title{
Cardiac dysfunction in acromegaly: evidence by pulsed wave tissue Doppler imaging
}

Giuseppe Mercuro, Sandra Zoncu, Paolo Colonna, Paolo Cherchi, Stefano Mariotti ${ }^{1}$, Francesca Pigliaru ${ }^{1}$, Laura Petrini ${ }^{1}$ and Sabino Iliceto

Department of Cardiovascular Sciences and ${ }^{1}$ Department of Endocrinology, Department of Medical Sciences, University of Cagliari, Cagliari, Italy

(Correspondence should be addressed to G Mercuro, Department of Cardiovascular Sciences, University of Cagliari, Via S. Giorgio, 12, O9124 Cagliari, Italy; Email: mercuro@pacs.unica.it)

\begin{abstract}
Objective: To verify whether the accuracy of data on myocardial function provided by pulsed-wave tissue Doppler imaging (PWTDI), a new echocardiographic application that allows quantitative measurements of myocardial wall velocities, could help towards a better understanding of the natural history of acromegalic cardiomyopathy.

Design: Eighteen patients with active acromegaly (ten men and eight women; mean age 48.0 \pm 15.0 years) with no other detectable cause of heart disease underwent PWTDI. Thirteen healthy individuals matched for age and body mass index acted as a control group.

Methods: Ejection fraction (EF), transmitral early/late diastolic velocity (E/A) ratio and isovolumic relaxation time (IVRT) were measured by conventional echocardiography; systolic peak (Sv) and early $(\mathrm{Ev})$ and late $(\mathrm{Av})$ diastolic peak velocities, Ev/Av ratio and regional IVRT (IVRTs) were obtained by PWTDI.

Results: All patients showed appreciably abnormal left ventricular global diastolic function represented by prolongation of the IVRT $(P<0.001)$. Using PWTDI we found a prolongation of IVRTs and inversion of the Ev/Av ratio. In addition, the Ev/Av ratio proved to be significantly negatively correlated with IVRT; this correlation was not present in the case of the E/A ratio. Furthermore, a decrease in Sv was detected in the basal segment of the lateral wall $(P<0.01)$, which had the greatest degree of diastolic dysfunction.

Conclusions: PWTDI confirmed the acknowledged diastolic dysfunction that accompanies acromegalic cardiomyopathy and highlighted the greater sensitivity of regional PWTDI with respect to global Doppler diastolic indexes. Furthermore, by revealing an impairment of regional systolic function in presence of a normal EF, the findings with PWTDI contradicted the largely accepted theory that systolic function remains normal for several years in patients affected by acromegalic cardiomyopathy.
\end{abstract}

European Journal of Endocrinology 143 363-369

\section{Introduction}

In acromegaly, an excess of growth hormone $(\mathrm{GH})$ stimulates the growth of various tissues (1). At the cardiac level, GH induces hypertrophy with interstitial myocardial fibrosis via direct and insulin-like growth factor-I (IGF-I)-mediated mechanisms $(2,3)$. Cardiac hypertrophy in acromegaly involves both ventricles simultaneously and is initiated in the absence of any increase in wall stress. As a consequence, wall stress may be decreased, which is at variance with the other forms of hypertrophy (2). In time, a specific cardiomyopathy with cardiac decompensation and arrhythmias $(2,4)$ may result. Echocardiographic studies of acromegalic patients have shown that the heart is involved from the early stages of the disease (5) and that, in the subclinical phase, left ventricular (LV) systolic function is normal, whereas diastolic function is impaired $(6,7)$.

Pulsed-wave tissue Doppler imaging (PWTDI), an echocardiographic method recently developed (8), allows quantitative measurements of the myocardial contraction and relaxation velocities of a selected myocardial segment to be obtained. The present study aimed to verify whether PWTDI could contribute towards a better understanding of the natural history of acromegalic cardiomyopathy, through its enhanced sensitivity to diastolic dysfunction, and identifying preliminary regional signs of systolic dysfunction, before the appearance of clinical symptoms of cardiac decompensation. 


\section{Participants and methods}

\section{Study population}

Eighteen outpatients with active acromegaly (ten men and eight women, mean ( \pm S.D.) age $48.0 \pm 15.0$ years, range 30-72 years) took part in the study. Diagnosis had been confirmed on the basis of typical clinical features and on the demonstration of a resting fasting serum GH concentration $>10 \mathrm{ng} / \mathrm{ml}$, not suppressed $(\geq 2 \mathrm{ng} / \mathrm{ml})$ after an oral glucose load. Increased ageadjusted plasma IGF-I concentrations were also documented in all the patients. At the time of examination, they all had serum GH $\geq 5.0 \mathrm{ng} / \mathrm{ml}$ (mean \pm S.D. $=29.8 \pm 21.7$, range of $5.0-83.0 \mathrm{ng} / \mathrm{ml}$; assessed as the mean of at least 10 samples over $24 \mathrm{~h}$ ) (Table 1 ). The plasma GH concentration was measured by radioimmunoassay using a commercially available kit (CIS bio international; Gif-sur-Yvette, France). The plasma IGF-I concentration was assayed using an immunoradiometric method (DSL; Diagnostic System Laboratories, Webstern, TX, USA). Normal laboratory ranges for both men and women were: $122-400 \mathrm{ng} / \mathrm{ml}$ between the ages of 19 and 39 years, $75-306 \mathrm{ng} / \mathrm{ml}$ from 40 to 54 years, $48-225 \mathrm{ng} / \mathrm{ml}$ for those older than 55 years. In all patients, imaging of the pituitary was obtained by computed tomography or magnetic resonance, showing a macroadenoma in all. Endocrine study documented a pure GH-secreting adenoma in fifteen of the patients and GH/prolactin (PRL)-secreting adenoma in three: $\mathrm{GH}$-secreting pituitary adenoma (twelve patients), GH- and PRL-secreting pituitary adenoma (two), GH-secreting pituitary macroadenoma (three), GH- and PRL-secreting pituitary macroadenoma (one patient). Table 1 shows the clinical data pertaining to the acromegalic patients and normal controls. All patients were affected by active acromegaly at the time of the study (duration of disease since onset of symptoms $6.3 \pm 7.3$ years). Three were newly diagnosed (over the 5 months immediately after the onset of symptoms) and had not yet been prescribed any pharmacological treatment. Fifteen of those with

Table 1 Biophysical characteristics, cardiovascular measurements and clinical data of acromegalic patients and normal individuals. Values are means \pm S.D.

\begin{tabular}{llc}
\hline Variable & $\begin{array}{l}\text { Acromegalic } \\
\text { patients }\end{array}$ & $\begin{array}{l}\text { Normal } \\
\text { individuals }\end{array}$ \\
\hline Age (years) & $48.0 \pm 15.0$ & $46 \pm 13$ \\
Sex (male/female) & $10 / 8$ & $7 / 6$ \\
Body mass index $\left(\mathrm{kg} / \mathrm{m}^{2}\right)$ & $27.8 \pm 5.3$ & $26.3 \pm 6.4$ \\
Office blood pressure $(\mathrm{mmHg})$ & & \\
$\quad$ Systolic & $129 \pm 13$ & $125 \pm 10$ \\
$\quad$ Diastolic & $80.0 \pm 8.6$ & $83 \pm 4$ \\
Heart rate (beats/min) & $68.0 \pm 13.9$ & $70 \pm 12.3$ \\
Plasma GH (ng/ml) & $29.8 \pm 21.7$ & $5.5 \pm 4$ \\
Plasma IGF-I (ng/ml) & $599 \pm 190$ & $225 \pm 60$ \\
Duration of disease (years) & $6.3 \pm 7.3$ & - \\
\hline
\end{tabular}

acromegaly had previously been unsuccessfully treated with surgery, radiotherapy and bromocriptine (single or in combination). Seven of the acromegalic patients (mean age $59 \pm 10$ years) were affected by borderline (two) or mild (five) hypertension that had been successfully treated with antihypertensive drugs. Thirteen healthy individuals with mean age, body mass index and a ratio of men to women comparable to that of the acromegalic patients acted as the control group. All the normal controls were normotensive. Neither acromegalic patients nor the normal controls were characterized by high total cholesterol and low-density lipoprotein, diabetes, obesity or habitual smoking.

\section{Study procedure}

The study was approved by the Ethics Committee of our University. Informed consent was obtained from all participants, who were familiarized with the instrumentation and the medical environment before undergoing testing. Besides the conventional techniques of M-Mode and two-dimensional echocardiography, all patients underwent PWTDI in order to obtain quantitative evaluation of the regional systolic/diastolic function. Tests were performed using ultrasound system equipped with tissue Doppler imaging capabilities (SSA380A; Toshiba Corp., Tochigi, Japan). All examinations were carried out by a single experienced echocardiographer and required both patients and controls to assume the left lateral decubitus position. Simultaneous electrocardiographic and phonocardiographic tracings were obtained.

\section{Conventional echocardiography}

A 2.5-MHz transducer was used for all M-Mode, twodimensional and Doppler echocardiographic examinations. Complete M-Mode, two-dimensional, spectral- and color-Doppler recordings were made in accordance with the American Society of Echocardiography recommendations (9). We measured ejection fraction (EF) and left ventricular (LV) mass in accordance with the method of Devereux (10): LV mass = 0.8 (ASE-cube LV mass) $+0.6 \mathrm{~g}$, and LV mass index (LVMI) by dividing LV mass by body surface area. Pulsed Doppler transmitral flow was obtained from a four-chamber apical view, with the sample volume placed at the level of the mitral valve leaflet tips. Early diastolic (E) and late diastolic (A) velocities of transmitral flow were measured and the $\mathrm{E} / \mathrm{A}$ ratio calculated. Isovolumic relaxation time (IVRT) was measured as interval from the aortic component of the second sound to E wave onset.

\section{PWTDI}

Technical background PWTDI is an echocardiographic method that uses the Doppler principle utilized in conventional color Doppler system to 
measure blood flow velocities - to provide measurements of ventricular wall motion velocity by positioning the sample volume within the myocardium. Velocity is slower $(<10 \mathrm{~cm} / \mathrm{s})$ and the Doppler signal amplitude greater (approximately $40 \mathrm{~dB}$ ) in walls than in blood flow. In the PWTDI method, low-amplitude blood flow signals are eliminated by gain adjustment to allow only high-amplitude Doppler signals from wall motion to enter the velocity calculation circuit (11).

Data acquisition Data were acquired by means of a commercial ultrasound system (SSA-380A; Toshiba Corp.), using a 3.5-MHz transducer. In each individual, PWTDI mapping of systolic and diastolic velocities along the LV provided visualization of six walls: lateral wall and posterior septum from four-chamber apical view, anterior and inferior walls from two-chamber apical view, and posterior wall and anterior septum from the long-axis view (12). Each LV wall was divided into three myocardial segments: basal, mid and apical segments. A sample volume of $3 \mathrm{~mm}$ was positioned in the center of all segments of the six LV walls. In order to obtain the highest-frequency wall Doppler shift, the ultrasonic Doppler beam was aligned in a position as parallel as possible to the motion of each myocardial wall. We chose to analyze three myocardial segments (basal lateral wall, basal posterior interventricular septum and basal posterior wall) because of the optimal quality of the Doppler spectra at their respective levels. We chose the basal segments because they have an important role in the LV sphincter system. Six consecutive beats were recorded during held expiration. Three distinct waves were obtained and measured by means of the PWTDI signal of each segment during each cardiac cycle: a systolic positive velocity wave (Sv), an early diastolic (Ev) negative wave, and a late diastolic (Av) negative wave. PWTDI of the lateral wall frequently shows two systolic peaks. The measurement of peak velocity was made on a large positive wave of the Doppler signal during the major part of systole and the Ev/Av ratio calculated. IVRT of each segment (IVRTs) was measured as the interval from the aortic component of the second sound to Ev-wave onset. All parameters were measured during four consecutive cardiac cycles and their mean value calculated.

PWTDI values of hypertensive patients did not influence the results.

\section{Reproducibility}

Intraobserver and interobserver variability, expressed as the mean values of the differences of the measurements, were assessed by analysis of seven randomly selected PWTDI recordings. Recordings were measured separately under blind conditions by two experienced echocardiographers. Repeated measurements were not made during the same scan session, but on separate days. Differences in observer bias were estimated for Sv, Ev, Av and IVRTs of each segment studied.

\section{Statistical analysis}

All group data are reported as means \pm s.D. Differences between control individuals and acromegalic patients were assessed by the Student's two-tailed $t$-test for unpaired observations. Correlations were calculated using Pearson's correlation coefficient. All calculated $P$ values are considered significant at $<0.05$.

\section{Results}

\section{Conventional echocardiography}

Table 2 shows the most significant morphologic and functional parameters. LVMI was significantly increased in acromegalic patients compared with that in healthy controls $(P<0.001)$, but did not correlate with the duration of disease $(r=0.355$, NS). In no patient was right ventricular hypertrophy detected. Hypertensive acromegalic patients had greater values of LVMI compared with those in normotensive acromegalic patients, but the difference was not significant $\left(151.8 \pm 17.5 \mathrm{~g} / \mathrm{m}^{2}\right.$ compared with $139.4 \pm$ $25.2 \mathrm{~g} / \mathrm{m}^{2}$ ). A normal systolic function assessed by EF was found in all patients. With regard to diastolic function, the $\mathrm{E} / \mathrm{A}$ ratio was decreased in patients with acromegaly (with $\mathrm{E} / \mathrm{A}$ ratio inversion in eight patients) in comparison with normal controls $(P<0.05)$; IVRT was increased $(P<0.001$; Table 2$)$.

No correlation was found between the above echocardiographic data and serum GH or IGF-I concentrations at the time of examination, nor with the disease duration.

\section{Other echocardiographic findings in acromegalic patients}

Results obtained were as follows: mitral valve prolapse in three patients, one with mild mitral regurgitation; mild mitral regurgitation without valve prolapse (four);

Table 2 Findings of conventional echocardiography in acromegalic patients and in normal individuals. Values are means \pm S.D.

\begin{tabular}{lcc}
\hline & $\begin{array}{l}\text { Acromegalic } \\
\text { patients } \\
(n=18)\end{array}$ & $\begin{array}{l}\text { Normal } \\
\text { individuals } \\
(n=13)\end{array}$ \\
\hline LVMI $\left(\mathrm{g} / \mathrm{m}^{2}\right)$ & $143.8 \pm 23.0^{\star *}$ & $97.5 \pm 17.8$ \\
EF $(\%)$ & $64.3 \pm 5.9$ & $66.0 \pm 6.6$ \\
Transmitral flow & $64.5 \pm 16.1$ & $72.0 \pm 14.8$ \\
E $(\mathrm{cm} / \mathrm{s})$ & $57.3 \pm 15.3$ & $49.7 \pm 12.9$ \\
A $(\mathrm{cm} / \mathrm{s})$ & $1.2 \pm 0.4^{*}$ & $1.6 \pm 0.5$ \\
E/A ratio & $114.1 \pm 9.8^{\star *}$ & $76.1 \pm 12.7$ \\
IVRT $(\mathrm{ms})$ & & \\
\hline
\end{tabular}

${ }^{\star} P<0.05,{ }^{* \star} P<0.001$ compared with normal individuals 
Basal lateral Segment

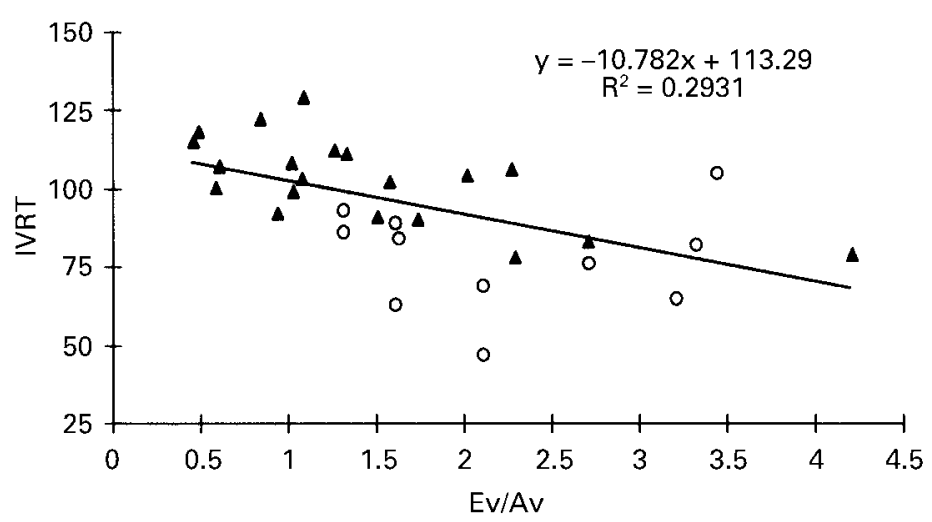

Basal interventricular Septum Segment

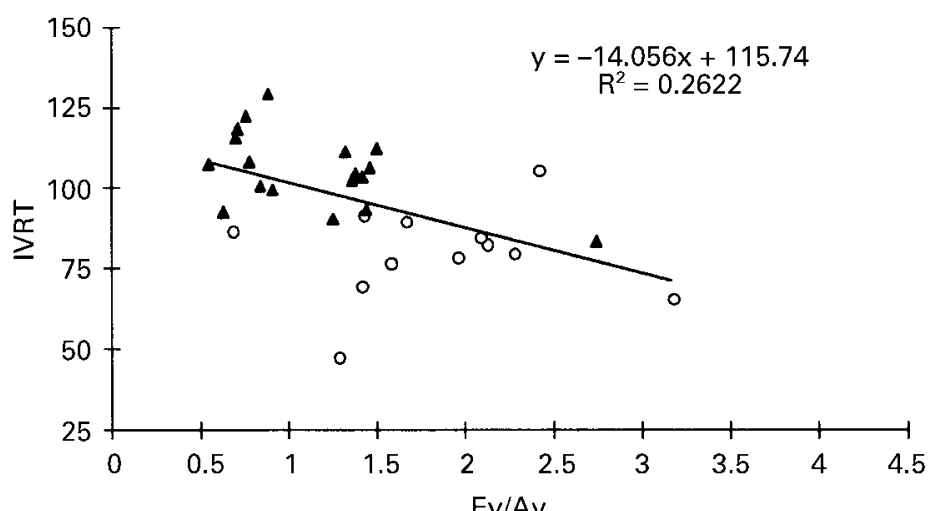

Basal Posterior Segment

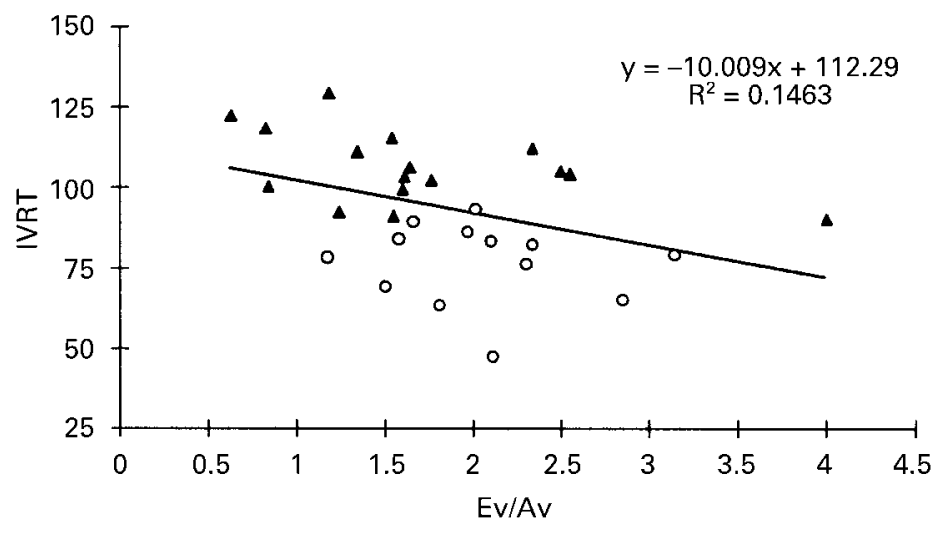

Mitral E/A

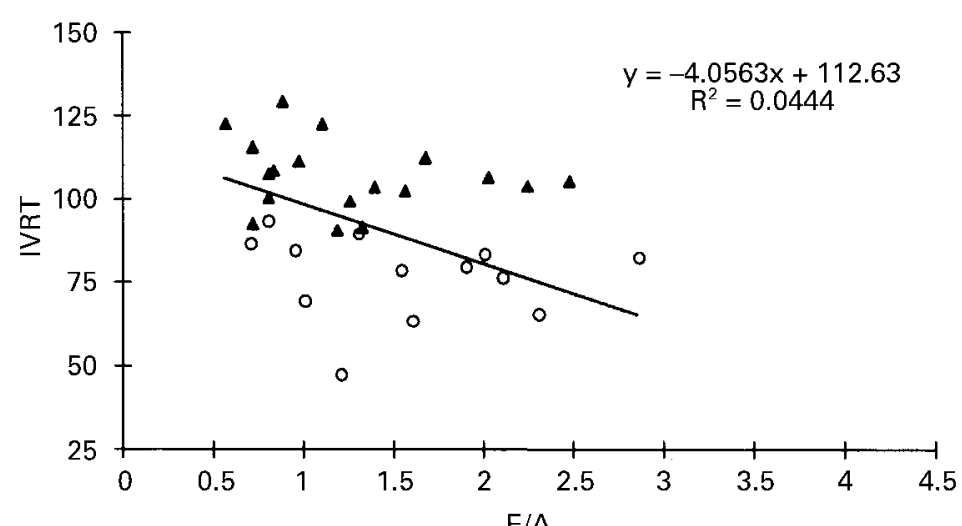

Figure 1 Relationships between IVRT and Ev/Av ratio of basal lateral wall segment (top left), basal posterior wall segment (top right), basal interventricular septum segment (bottom left) and between IVRT and mitral E/A ratio (bottom right). $\mathbf{\Lambda}$, Acromegalic patients; $\bigcirc$, normal individuals. 
Table 3 Regional systolic and diastolic peak velocities in acromegalic patients and in normal individuals. Values are means \pm S.D.

\begin{tabular}{|c|c|c|}
\hline Segment & $\begin{array}{l}\text { Acromegalic } \\
\text { patients } \\
(n=18)\end{array}$ & $\begin{array}{l}\text { Normal } \\
\text { individuals } \\
(n=13)\end{array}$ \\
\hline \multicolumn{3}{|c|}{ Basel lateral wall (4 Ch) } \\
\hline $\mathrm{Sv}(\mathrm{cm} / \mathrm{s})$ & $8.0 \pm 1.7^{*}$ & $10.3 \pm 1.8$ \\
\hline $\mathrm{Ev}(\mathrm{cm} / \mathrm{s})$ & $-8.3 \pm 2.1$ & $-14.8 \pm 3.5$ \\
\hline$A v(\mathrm{~cm} / \mathrm{s})$ & $-11.5 \pm 2.6$ & $-6.8 \pm 1.6$ \\
\hline Ev/Av ratio & $0.7 \pm 0.3^{\star \star \star}$ & $2.3 \pm 0.9$ \\
\hline IVRTs (ms) & $104 \pm 10.3^{\star \star *}$ & $71.7 \pm 13.5$ \\
\hline \multicolumn{3}{|c|}{ Basal posterior septum (4 Ch) } \\
\hline $\mathrm{Sv}(\mathrm{cm} / \mathrm{s})$ & $8.0 \pm 0.6$ & $8.5 \pm 1.0$ \\
\hline $\mathrm{Ev}(\mathrm{cm} / \mathrm{s})$ & $-10.7 \pm 2.7$ & $-12.6 \pm 2.3$ \\
\hline$A v(\mathrm{~cm} / \mathrm{s})$ & $-10.0 \pm 2.4$ & $-9.0 \pm 2.0$ \\
\hline Ev/Av ratio & $1.1 \pm 0.3^{*}$ & $1.4 \pm 0.5$ \\
\hline IVRTs (ms) & $109.7 \pm 10.1^{\star \star \star}$ & $75.8 \pm 14.3$ \\
\hline \multicolumn{3}{|c|}{ Basal posterior wall (LAX) } \\
\hline $\mathrm{Sv}(\mathrm{cm} / \mathrm{s})$ & $7.0 \pm 1.1$ & $7.7 \pm 1.5$ \\
\hline $\mathrm{Ev}(\mathrm{cm} / \mathrm{s})$ & $-10.5 \pm 2.0$ & $-11.1 \pm 3.8$ \\
\hline$A v(\mathrm{~cm} / \mathrm{s})$ & $-7.0 \pm 2.5$ & $-5.6 \pm 2.0$ \\
\hline Ev/Av ratio & $1.5 \pm 0.6^{\star *}$ & $2.0 \pm 0.5$ \\
\hline IVRTs (ms) & $95.2 \pm 12.9^{\star \star}$ & $69.8 \pm 17.1$ \\
\hline
\end{tabular}

$4 \mathrm{Ch}$, four-chamber apical view; LAX, parasternal long axis view. ${ }^{\star} P<0.01,{ }^{*} P<0.005,{ }^{* \star *} P<0.001$ compared with normal individuals.

enlarged left atrium (seven); interatrial septum bulging (four); biatrial enlargement (one); mild annuloaortic ectasia (four patients, three of whom had minimal aortic regurgitation); mild aortic regurgitation without annuloaortic ectasia (one); slightly increased systolic pressure of the right ventricle (three). These findings were not more than would be expected.

\section{PWTDI}

Table 3 summarizes myocardial velocities of the three myocardial segments analyzed. In acromegalic patients we observed a significant involvement of both the Ev/Av ratio and IVRTs, with a decrease or invertion of the former $(P<0.001$ in basal lateral wall segment; $P<0.005$ in basal posterior wall segment; $P<0.01$ in basal posterior septum segment) and prolongation of the latter $(P<0.005$ in the basal posterior wall segment; $P<0.001$ in the two other segments). Values for E/A ratio and Ev/Av ratio were correlated with IVRT, a parameter that was found to be equally modified in all patients studied. The Ev/Av ratio of all myocardial segments was seen to correlate with IVRT (basal lateral wall segment $r=-0.54, P<0.002$; basal posterior wall segment $r=-0.38, P<0.05$; basal posterior interventricular septum $r=-0.51, P<0.005)$, whereas the E/A ratio did not correlate with IVRT ( $r=-0.29$, NS; Fig. 1).

In this study the mitral $\mathrm{E} / \mathrm{A}$ ratio did not correlate with the duration of disease $(r=-0.11$, NS). We are of the opinion that this lack of a correlation does not weaken the results, because it is known that the mitral $\mathrm{E} / \mathrm{A}$ ratio is influenced by several factors (age, heart
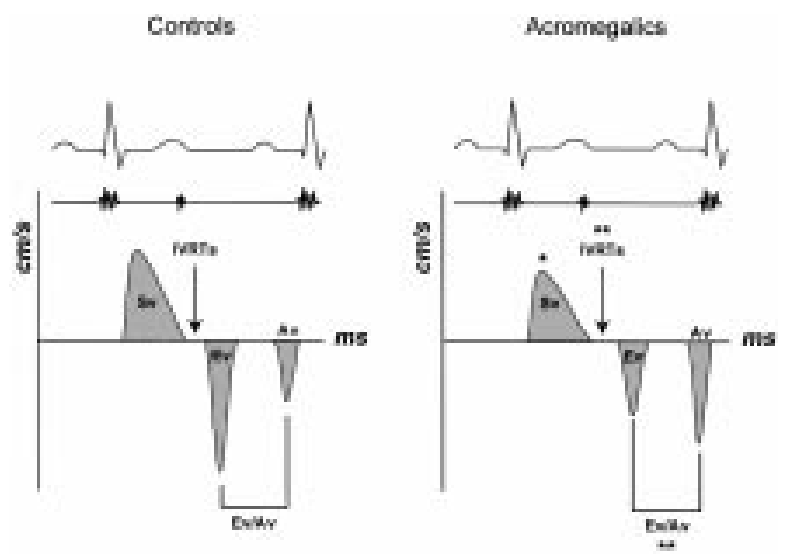

Figure 2 Lateral wall basal segment: electrocardiographic and phonocardiographic traces, and PWTDI pattern in the control individuals (left: $n=13$, seven men and six women), and in the cohort of acromegalic patients (right: $n=18,10$ men and eight women). ${ }^{\star} P<0.01,{ }^{\star \star} P<0.001$ compared with control individuals.

rate, preload and afterload). Mitral E/A significantly correlated with Ev/Av ratio of the three segments analyzed: basal lateral segment $(r=0.885, P<0.001)$, basal posterior segment $(r=0.518, P<0.05)$ and basal interventricular septum segment $(r=0.862$, $P<0.001$ )

When compared with that in normal controls, the basal lateral wall segment of acromegalic patients showed a significant decrease in Sv $(P<0.01)$ (Table 3; Fig. 2). A similar trend was observed in the basal posterior wall segment, although this difference was not statistically significant (Table 3). PWTDI values of hypertensive patients did not influence the results.

Again, no significant correlation was found between any of the above echocardiographic parameters and the serum GH or IGF-I concentrations, or with the disease duration.

\section{Reproducibility}

The means and standard deviations of the intraobserver and inter-observer differences are reported in Table 4.

\section{Discussion}

\section{Acromegaly and the heart}

Acromegaly is a clinical condition characterized by chronic GH excess, the main cause of which is the presence of a GH pituitary adenoma (1). Further to a direct anabolic effect on cardiac muscle (3), the majority of the growth-promoting effects of $\mathrm{GH}$ are mediated by IGF-I, which induces cellular proliferation either as an endocrine substance through the bloodstream or by local production within the tissue (1). Cardiac hypertrophy is a frequent finding in acromegaly. In time, 
Table 4 Intra-observer and inter-observer variability.

\begin{tabular}{|c|c|c|c|c|}
\hline \multirow[b]{2}{*}{ Parameter } & \multicolumn{2}{|c|}{ Intraobserver differences } & \multicolumn{2}{|c|}{ Interobsever differences } \\
\hline & Mean \pm S.D. & $P$ & Mean \pm S.D. & $P$ \\
\hline \multicolumn{5}{|c|}{ Basal lateral wall (4 Ch) } \\
\hline $\mathrm{Sv}(\mathrm{cm} / \mathrm{s})$ & $0.17 \pm 0.29$ & 0.17 & $0.75 \pm 0.45$ & 0.22 \\
\hline $\mathrm{Ev}(\mathrm{cm} / \mathrm{s})$ & $0.14 \pm 0.22$ & 0.17 & $0.91 \pm 0.50$ & 0.10 \\
\hline $\mathrm{Av}(\mathrm{cm} / \mathrm{s})$ & $0.21 \pm 0.33$ & 0.18 & $0.70 \pm 0.35$ & 0.31 \\
\hline IVRTs (ms) & $2.43 \pm 5.59$ & 0.43 & $6.83 \pm 2.93$ & 0.08 \\
\hline \multicolumn{5}{|c|}{ Basal posterior septum (4 Ch) } \\
\hline $\mathrm{Sv}(\mathrm{cm} / \mathrm{s})$ & $0.28 \pm 0.55$ & 0.36 & $0.63 \pm 0.33$ & 0.37 \\
\hline $\mathrm{Ev}(\mathrm{cm} / \mathrm{s})$ & $0.18 \pm 0.41$ & 0.37 & $0.64 \pm 0.42$ & 0.41 \\
\hline$A v(\mathrm{~cm} / \mathrm{s})$ & $0.11 \pm 0.19$ & 0.36 & $0.70 \pm 0.41$ & 0.85 \\
\hline IVRTs (ms) & $1 \pm 1.73$ & 0.36 & $6.00 \pm 3.52$ & 0.26 \\
\hline \multicolumn{5}{|c|}{ Basal posterior wall (LAX) } \\
\hline $\mathrm{Sv}(\mathrm{cm} / \mathrm{s})$ & $0.003 \pm 0.008$ & 0.35 & $0.80 \pm 0.33$ & 0.30 \\
\hline $\mathrm{Ev}(\mathrm{cm} / \mathrm{s})$ & $0.17 \pm 0.41$ & 0.38 & $0.94 \pm 0.87$ & 0.19 \\
\hline$A v(\mathrm{~cm} / \mathrm{s})$ & $0.05 \pm 0.13$ & 0.36 & $0.79 \pm 0.43$ & 0.37 \\
\hline IVRTs (ms) & $1 \pm 2.45$ & 0.37 & $9.67 \pm 4.18$ & 0.08 \\
\hline
\end{tabular}

myocardial degeneration, coupled with conspicuous interstitial tissue fibrosis (13), are destined to generate cardiovascular complications such as arrhythmias (4), hypertension and cardiac failure (2).

\section{Conventional echocardiography: global systolic/diastolic function}

Cardiac function and anatomy in acromegaly have been widely investigated by echocardiographic techniques. An increase in left and right ventricular mass induced by $\mathrm{GH}$ excess has been documented largely by this means $(5,14)$. In the majority of patients, cardiac hypertrophy was concentric and independent of preload and afterload modifications (3). Thus, as a result of myocardial thickening and normal ventricular tension, acromegaly represents a unique model of cardiac hypertrophy associated with normal or decreased wall stress.

When compared with healthy subjects, all acromegalic patients were found to be affected by cardiac hypertrophy. The degree of increased LV mass induced by GH excess correlated with the duration of the disease, but not with GH and IGF-I plasma concentrations (data not shown), thereby confirming that its development is largely time-dependent $(6,13,15,16)$.

A modified diastolic filling pattern of transmitral flow and a prolongation of IVRT were found in association with increased LV mass. This abnormality appears to be the key defect in LV dysfunction in acromegalic cardiomyopathy, and depends on altered relaxation and increased stiffness caused by the hypertrophy and interstitial fibrosis.

In accordance with data in literature $(5,6)$, in our acromegalic patients conventional echocardiography did not reveal modifications of systolic function compared with that in healthy individuals.

\section{PWTDI: regional systolic/diastolic function}

This innovative technique allowed a more detailed evaluation of the aforementioned abnormal LV filling and relaxation pattern in acromegalic patients. Use of PWTDI demonstrated a decreased or inverted Ev/Av ratio and a prolongation of IVRTs in each myocardial segment examined. On correlation of either mitral E/A ratio or Ev/Av ratio of each segment with IVRT, PWTDI indexes were seen to act as indicators of abnormal left ventricular diastolic filling, to a greater degree than transmitral Doppler indexes of conventional echocardiography. A possible explanation could be afforded by the fact that regional Ev/Av ratio is less affected than the mitral E/A ratio by extrinsic factors (such as loading conditions, heart rate, age) that influence the diastole. A further reason for the increased sensitivity shown by PWTDI in recognizing diastolic dysfunction could be represented by the heterogeneity of regional myocardial contraction and relaxation. In agreement with previous evidence that the relaxation activity in the longitudinal axis is predominant in the lateral aspect of the left ventricular wall (17), in our study the lateral walls were shown to be the worst affected.

Considerable echocardiographic evidence supports the view that uncomplicated acromegaly is accompanied by a normal systolic function $(5,6)$. Radionuclide angiography, revealing an EF that was normal at rest but increased by less than 5\% during exercise, was the only technique capable of revealing an impaired cardiac systolic performance, at least in conditions of stress (18, 19). In the present study, PWTDI - even in basal resting conditions - was able to highlight a worsening of the systolic cardiac performance in acromegalic patients, represented by a decrease in the regional $\mathrm{Sv}$ at the level of the basal lateral wall segment. This finding, observed in patients with a clinically asymptomatic acromegalic cardiomyopathy, demonstrates a greater diagnostic 
sensitivity of PWTDI compared with conventional echocardiography. The regional limitation of systolic myocardial dysfunction to the lateral wall revealed by PWTDI could be ascribed to the essential contribution of this region to longitudinal LV systolic shortening. It has in fact been demonstrated that, compared with the septum, the lateral wall is characterized by greater longitudinal contractile activity in normal individuals (17); it might be because of this particular working load that the basal lateral wall segment was the first myocardial region to show signs of systolic dysfunction in acromegalic cardiomyopathy.

In the present investigation no significant correlation was found between any of the conventional and PWTDI echocardiographic parameters and the serum GH or IGF-I concentration at the time of the study. This finding is probably due to the particular composition of the study group: although all patients displayed active disease, they were very heterogeneous in term of age and disease duration. Furthermore, most of them have been followed at different Institutions in the previous years and data needed to calculate the area under the curve of mean GH level at any year since either diagnosis or onset of symptoms (which represents a good index of total tissue exposure to $\mathrm{GH}$ (20)) were not available. We recognize that this is an important limitation of this study, because of its preliminary nature: our main intention was to select as many patients with active acromegaly as possible, to ascertain the potential usefulness of PWTDI in this disease. Nevertheless, we are confident that this echocardiographic technique will be much more conveniently used in longitudinal studies involving acromegalic patients evaluated before and during or after treatment.

In conclusion, compared with conventional echocardiography, PWTDI provided new physiopathological details of the altered ventricular function in acromegalic cardiomyopathy and, further to the theoretical considerations, proved to be an efficient tool in the early detection of diastolic dysfunction induced by the disease. The successful initial application of PWTDI in studying acromegaly suggests its possible use in revealing early regional dysfunction in the entire field of cardiomyopathies. In this repect, it could be used for quantitative measurement of decreased regional function in the absence of clinical and conventional echocardiographic signs of a systolic cardiac insufficiency.

Longitudinal studies carried out before and after treatment are needed to assess whether, and to what extent, this new echocardiographic technique would be useful for clinical management of patients with acromegaly.

\section{Acknowledgements}

We gratefully acknowledge Maria Leo for her excellent graphic assistance.

\section{References}

1 Melmed S. Acromegaly. New England Journal of Medicine 1990322 966-977.

2 Saccà L, Cittadini A \& Fazio S. Growth hormone and the heart. Endocrine Reviews 199415 555-571.

3 Cittadini A, Stromer H, Katz SE, Clark R, Moses AC, Morgan JP et al. Differential cardiac effects of growth hormone and insulinlike growth factor-1 in the rat. A combined in vivo and in vitro evaluation. Circulation 199693 800-809.

4 Kahaly G, Olshausen KV, Mohr-Kahaly S , Erbel R, Boor S, Beyer J \& Meyer J. Arrhythmia profile in acromegaly. European Heart Journal 199213 51-56.

5 Fazio S, Cittadini A, Sabatini D, Merola B, Colao AM, Biondi B et al. Evidence for biventricular involvement in acromegaly: a Doppler echocardiographic study. European Heart Journal 199314 26-33.

6 Fazio S, Sabatini D, Cittadini A, Biondi B, Merola B, Colao A et al. Ormone della crescita e cuore. Cardiologia 199338 513-518.

7 Lusiani L, Ronsisvalle G, Visonà A, Castellani V, Bonanome A, Pagnan A et al. Acromegalic cardiomyopathy. An echocardiographic study. Journal of Endocrinological Investigation 198811 159-164.

8 Isaaz K, Thompson A, Ethevenot G, Cloez JL, Brembilla B \& Pernot C. Doppler echocardiographic measurement of low velocity motion of the left ventricular posterior wall. American Journal of Cardiology 198964 66-75.

9 Sahn DJ. DeMaria A, Kisslo J \& Weyman A. Recommendations regarding quantification in M-Mode echocardiography: results of a survey of echocardiographic measurements. Circulation 1978 58 1072-1083.

10 Devereux RB. Detection of left ventricular hypertrophy by M-Mode echocardiography. Anatomic validation. Standardization, and comparison to other methods. Hypertension 19879 (Suppl II) 19-26.

11 Yamazaki N. Principles of Doppler tissue velocity measurements. In Atlas of Tissue Doppler Echocardiography, pp 9-15. Eds Erbel R, Nesser HJ \& Drozdz J. Heidelberg: Springer-Verlag 1995.

12 Schiller NB, Shan PM. Crawford M. DeMaria A. Devereux R, Feigenbaum $\mathrm{H}$ et al. Recommendation for quantitative of the left ventricle by two-dimensional echocardiography. Journal of American Society of Echocardiography $19892358-367$.

13 Lie JT \& Grossman SJ. Pathology of the heart in acromegaly: anatomic findings in 27 autopsied patients. American Heart Journal $198010041-52$.

14 Hradec J, Marek J, Kral J, Janota T, Poloniecki J \& Malik M. Longterm echocardiographic follow-up of acromegalic heart disease. American Journal of Cardiology 199372 205-210.

15 Lim MJ, Barkan AL \& Buda AJ. Rapid reduction of left ventricular hypertrophy in acromegaly after suppression of growth hormone hypersecretion. Annals of Internal Medicine 1992117 719-726.

16 McGuffin Jr WL, Sherman BM, Roth J, Gorden P, Kahn CR, Roberts WC et al. Acromegaly and cardiovascular disorders. A prospective study. Annals of Internal Medicine 197481 11-18.

17 Galiuto L, Ignone G \& DeMaria A. Contraction and relaxation velocities of the normal left ventricle using pulsed-wave tissue Doppler echocardiography. American Journal of Cardiology 1998 81 609-614.

18 Fazio S, Cittadini A, Cuocolo A, Merola B, Sabatini D, Colao A et al. Impaired cardiac performance is a distinct feature of uncomplicated acromegaly. Journal of Clinical Endocrinology and Metabolism $199479441-446$.

19 Fazio S, Sabatini D, Cittadini A, Cocozza M, Cuocolo A, Merola B et al. Cardiac involvement in active uncomplicated acromegaly. Internal Journal of Angina 19965 55-58.

20 Jenkis PJ, Fairclough PD, Richards T, Lowe DG, Monson J, Grossman A et al. Acromegaly, colonic polyps and carcinoma. Clinical Endocrinology 199747 17-22.

Received 25 June 1999

Accepted 30 May 2000 